\title{
Lumbar vertebral canal stenosis: concept of morphometric and radiometric study of the human lumbar vertebral canal
}

\author{
Mohammed El-Rakhawy, Abd El-Rahman El-Shahat, Ibrahim Labib, Ehab Abdulaziz \\ Department of Anatomy, Faculty of Medicine, Cairo University, Cairo, Egypt
}

\begin{abstract}
Objectives: Vertebral canal stenosis has attracted the attention of anatomists and clinician as an important structural change with significant radiological and clinical implications. Narrowing of all diameters of the vertebral foramen with age could be responsible as a factor which might produce back pain. The aim of the present study was to estimate the averages anatomical changes in the transverse and anteroposterior diameters of the lumbar vertebral canal in Egyptian population to establish a clue to the underlying some causes of the low-back pain of unknown etiology.

Methods: The present study investigated the lumbar part of the vertebral column of 20 adult skeletons and 200 plain Xrays of normal living subjects (100 males and 100 females) for both morphometric and radiometric analyses.

Results: The mean width of the body of vertebrae showed gradual increase with the exception at L4 in dry bones. In addition, the mean width and depth of the vertebral foramina showed a gradual increase with the exception of L3 in dry bones. The study recorded a positive relationship between the mean width of the vertebral foramen and that of the body. The mean vertebral foramen width/body ratio was 0.6 except at L3 and L5 where the ratio was 0.5 .

Conclusion: The present study has shown a narrower depth of the lumbar vertebral canal in Egyptian population. L3 remains the center point for transition in the dimensions and hence more susceptible to stenosis and spinal nerve compression. This study has also shown that the ratio between the width of body and foramen of lumbar vertebrae remains constant. By this ratio it may be possible to predict any lumbar vertebral anomalies or vertebral canal stenoses and to give some explanation about low-back pain of unknown etiology.
\end{abstract}

Key words: vertebral canal; lumbar stenosis; low-back pain

Anatomy 2010; 4: 51-62, () 2010 TSACA

\section{Introduction}

Narrowing of the lumbar vertebral canal, referred to as lumbar spinal stenosis, is a rising phenomenon due to aging of the population, and has been diagnosed increasingly in the last two decades. The pathology of this disease is most typically due to degenerative changes. ${ }^{1-3}$ Transverse diameter of the lumbar vertebral canal (inter- pedicular distance) is a reliable index for the assessment of the size of the canal. ${ }^{4-6}$ Measurements of the interpedicular distance may be a preliminary, but useful aid in the diagnosis of the lumbar canal stenosis syndrome. ${ }^{7,8}$ Diagnostic imaging (radiographs and MRI scans) continues to play a pivotal role in the diagnosis and clinical decision making. Amonoo-Kuofi ${ }^{9}$ and Speciale et al., ${ }^{8}$ in their studies, have reported variable values of the ratio 
between the interpedicular distance and vertebral body width for different races at different ages amongst the male and female sexes.

Developmental or acquired narrowing of lumbar canal may lead to compression of the nerve roots and cause low-back pain. ${ }^{1,30}$ According to Haig et al., lumbar spinal stenosis is a common source of back and lower extremity pain accompanied by other neurological symptoms. ${ }^{11}$

Recognition and management of problems inherent to lumbar canal stenosis require understanding of the diverse anatomical changes and careful correlation with a wide spectrum of fluctuating clinical manifestations. ${ }^{11,12}$ Haig et al. ${ }^{11}$ and Geisser et al. ${ }^{12}$ demonstrated that there was little relationship between central canal size and clinical symptoms among individuals with a clinical diagnosis of lumbar spinal stenosis. Amonoo-Kuofi et al. ${ }^{13}$ and Agur $^{14}$ have reported a small and triangular vertebral foramina with "pinched" lateral angles at L5. According to the Garfin et al. ${ }^{15}$ and Ciricillo and Weinstein, ${ }^{16}$ stenosis of the vertebral canal in the lumbar region is a common finding in patients especially over 55 years of age. They have also pointed out that some patients could be born with vertebral canal stenosis (congenital stenosis), but the majority of cases are acquired. Geisser et al. ${ }^{12}$ and Zarzur $^{17}$ have stressed the fact that the shape of the human lumbar vertebral canal is not exclusively triangular and it varies at different levels.

The aim of the present study is to estimate and analyze the averages of the transverse and anteroposterior diameters of the lumbar vertebral canal and to clarify the morphological patterns of this canal in a sample of adult Egyptians of both sexes. These data may give a clue to the underlying causes of what is described as low-back pain of unknown etiology.

\section{Materials and Methods}

The present study included 100 lumbar vertebrae (L1-L5) from 20 adult skeletons and radiological examination of lumbar part of vertebral column of 200 normal living subjects.

\section{The dry bone study}

The dry bones were obtained from the Anatomy Department, Faculty of Medicine, Cairo University. Lumbar vertebrae from L1 to L5 were first radiographed to identify any apparent internal abnormalities to be excluded from the study. Screened specimens were then prepared by completely removing any remaining soft tissue from the vertebrae by careful piecemeal dissection. Vertebrae with abnormal external features due to trauma, degenerative changes or congenital anomalies were excluded. The dried bones were subsequently subjected to external morphometrical examinations. With the use of a sliding caliper measurements were carried out twice to exclude observer error, and the means of the recorded values were determined. The various dimensions measured in the current study for the lumbar vertebrae were according to those outlined by Amonoo-Kuofi and Panjabi et al. ${ }^{7,18}$

The measurements estimated from each vertebra:

1. Vertebral body width (VBW): Between the narrowest points across the middle of the sides of the vertebra (at the waist) (Figure 1a)

2. Vertebral foramen width (VFW) (interpedicular diameter): Between the midpoints on the upper margins of the two pedicles (Figure 1b).

3. Vertebral foramen depth (VFD) (anteroposterior diameter): Between the deepest point on the concavity of the posterior border of the upper surface of the body and the site of meeting of the upper borders of the two laminae (upper aspect of the root of the spine) (Figure 1b).

The correlation between vertebral foramen width and vertebral body width was obtained by determining the VFW/VBW ratio as follows:

$$
\mathrm{VFW} / \mathrm{VBW}=\frac{\text { Mean vertebral foramen width }}{\text { Mean vertebral body width }}
$$

\section{The radiometric study in livings}

Radiographic study of the lumbar part of vertebral column was performed on 200 normal adult subjects, 
Figure 1. A diagram showing different views of the different parts of a lumbar vertebra. a: front view; b: top view; VBW: vertebral body width; VFW: vertebral foramen width; VFD: vertebral foramen depth.

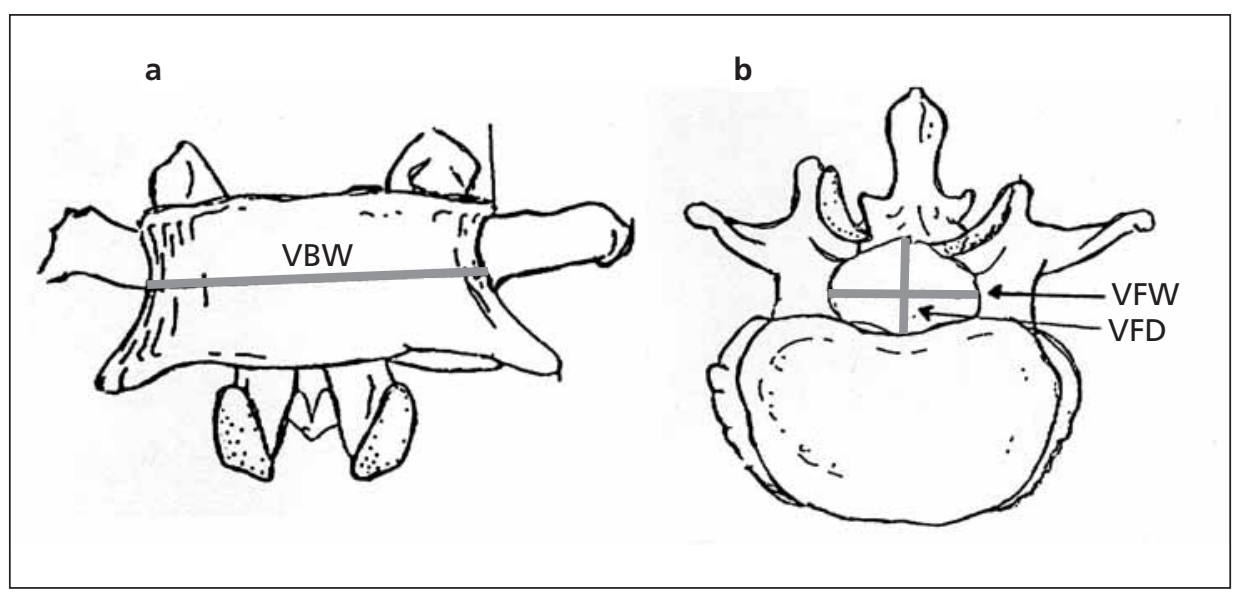

100 males and 100 females by taking anteroposterior and lateral views for each case. The age of the individuals examined ranged between 20 to 70 years with a mean age of 48 years. The subjects were selected from patients undergoing diagnostic radiology for abdominal or genitourinary complaints or patients attending the radiology department for a radiological investigation in regions other than the vertebral column. Individuals complaining of low-back pain and those having a history of surgery for back pain, trauma to the back and deformities or anomalies of the vertebral column were excluded. No pregnant female was included in this study. All the investigations and materials which were used in the study for that required permissions were taken from appropriate forms within the university and all the methods were followed in-line with international ethics and values.

All lateral radiographs were taken in the lateral recumbent position with the hips and knees flexed to $135^{\circ}$ in order to relax the lumbar ligaments. All radiographs of the lumbar part of vertebral column were taken with an anode-film distance $100 \mathrm{~cm}$ and centered at L3 that include the whole of the lumbar vertebral column. ${ }^{19}$ The radiographs were subjected to radiometric study with the following precautions applied:

- All measurements were made directly from plain radiographs.

- Distances were measured to the nearest $0.05 \mathrm{~cm}$.

- Magnification correction factor of the radiographs which were calculated according to Milton and
Tsokos $^{20}$ for the anteroposterior and lateral projections, to render the radiological measurement relevant in clinical practice:

The actual dimension of the object filmed = the dimension seen on the film $\times$ magnification factor.

The magnification correction factor was found to be 0.86 for anteroposterior projection and 0.77 for the lateral projection.

The measurements estimated from the radiographs:

1. Transverse diameter of the vertebral body was measured according to Grados et al. ${ }^{21}$ as the minimum distance across the waist of the vertebra (Figure 2).

2. Measurements for vertebral foramina were made according to Amonoo-Kuofi, ${ }^{7}$ Amonoo-Kuofi et al., ${ }^{13}$ and Weber and deKlerk ${ }^{22}$ including:

- Transverse diameter of the vertebral foramen (interpedicular distance): Measured as the minimum distance between the mid points on the medial surfaces of the pedicles of the same vertebra seen in anterior view (Figure 2).

- Anteroposterior diameter of the vertebral foramen: Obtained on the lateral projection and measured according to Amonoo-Kuofi et al. ${ }^{13}$ from the middle of the posterior edge of the body of vertebra to the posterior limit of the vertebral foramen that coincides with a line connecting the apex of the superior to the inverted apex of the inferior articular facet (Figure 3). 


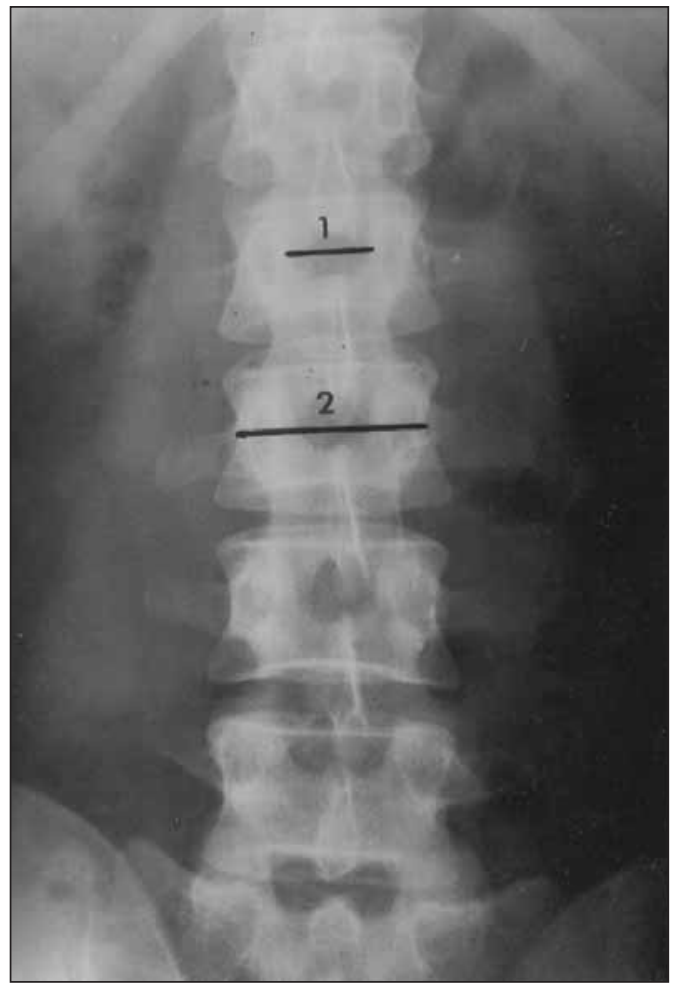

Figure 2. An anteroposterior radiograph of the lumbar part of a vertebral column showing the following measured diameters. 1: transverse diameter of the vertebral foramen (interpedicular distance); 2: transverse diameter of the vertebral body.

\section{Statistical study}

Analysis of the data was done using the Statistical Package for Social Sciences (SPSS). Frequency distributions of all variables were produced using suitable tables and graphs. All p values were based on 2-sided test, and the cutoff value for statistical significance was set at 0.05 . Independent student's t-test was used to test differences between two means.

\section{Results}

In dry bones, the shape of the lumbar vertebral foramen was variable. In the upper lumbar vertebrae (L1 and L2), the foramen was oblong (with wide transverse diameter) or triangular in shape with the base of the triangle (long border) directed anteriorly towards the vertebral body. The apex of the triangle was directed posteriorly

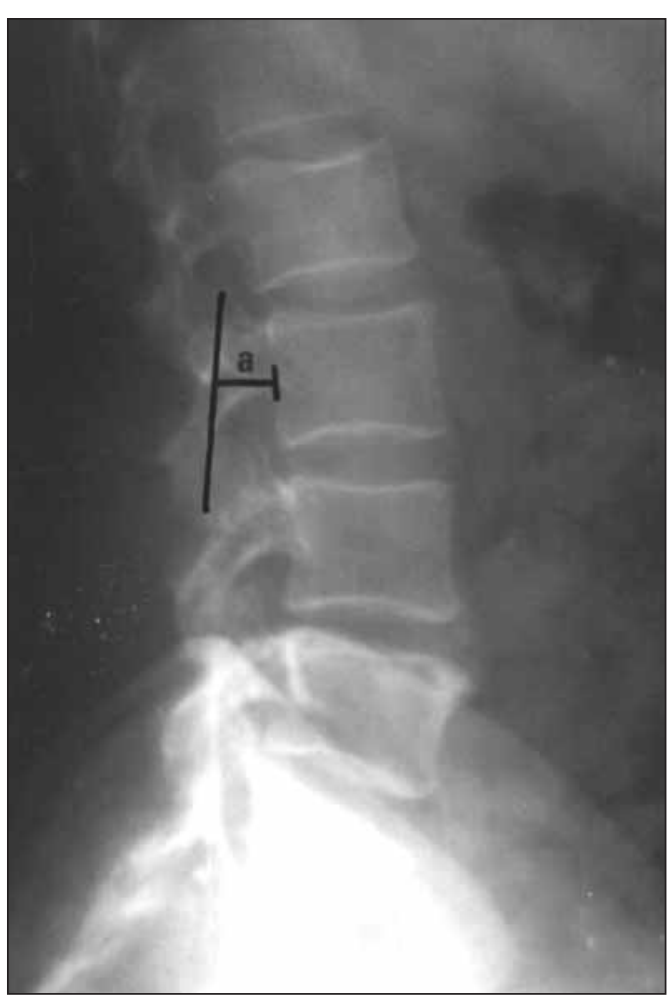

Figure 3. A lateral radiograph of the lumbar part of a vertebral column showing the anteroposterior diameter (a) of the lumbar vertebral foramen.

in the midline, the sides (right and left) were of equal length while the lateral angles of the foramen were less acute in the upper than the lower lumbar vertebrae (Figures 4, 5 and 6). In the lower lumbar region (L4L5), the vertebral foramen was nearly trefoil in shape (Figure 6). In the mid-lumbar region (L3), the vertebral foramen was triangular in shape with the two lateral angles more acute than in the first two lumbar vertebrae (Figure 5). However, these lateral angles (lateral recesses) were smaller in the fourth and fifth lumbar vertebrae than the upper ones (Figures 5 and $\mathbf{6}$ ).

The mean width or transverse diameter of the lumbar vertebral foramen (VFW) of dry bones increased from $21.6 \mathrm{~mm}$ at $\mathrm{L} 1$ to $22.5 \mathrm{~mm}$ at $\mathrm{L} 2$ then decreased to 21.4 $\mathrm{mm}$ at $\mathrm{L} 3$ to re-increase to $23.5 \mathrm{~mm}$ at $\mathrm{L} 4$ and $25.1 \mathrm{~mm}$ at L5. The mean vertebral foramen depth (VFD) increased from $14.9 \mathrm{~mm}$ at L1 to $15 \mathrm{~mm}$ at L2 to 
Figure 4. Photographs of the superior views of the upper two lumbar vertebrae with different shapes of vertebral foramina. a: L1 with oblong vertebral foramen; b: L2 with triangle vertebral foramen.

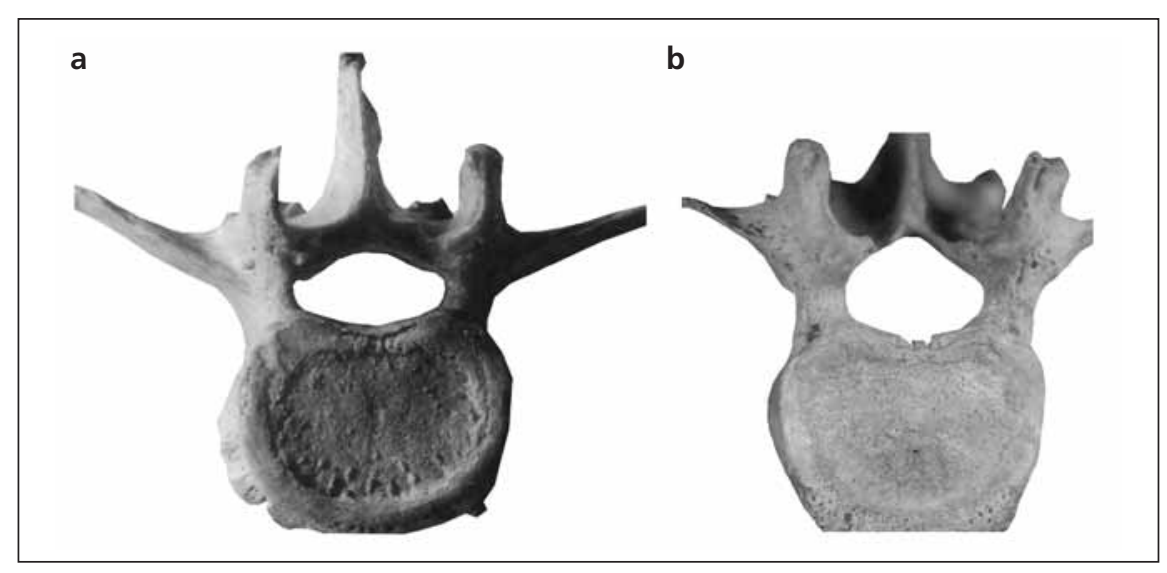

decrease suddenly to $13.4 \mathrm{~mm}$ at L3 then showed a slight increase $15.4 \mathrm{~mm}$ at L4 and $15.6 \mathrm{~mm}$ at L5 (Table 1).

In dry bones, the study recorded that the ratio of the vertebral foramen width (VFW) to vertebral body width (VBW) was constant at both L1 and L2 levels being 0.60 but at L3 level, it showed a drop to 0.53 and then it increased again to 0.60 at L4 level and finally the ratio dropped to 0.53 at L5. In radiological study, however, the ratio was found to be decreasing from 0.57 at L1 to 0.56 at L2 and then showed sudden decrease to 0.53 at L4 and 0.51 at L5 level (Table 2).

According to whether the vertebral foramen width (VFW) is increasing, constant or decreasing throughout the lumbar region, the following morphological patterns or shapes can be identified for the lumbar vertebral canal (Figure 7):

Pattern I demonstrated that the width of the canal increased from L1 to L2 then narrowed at L3 and rewidened again from L3 down to L5. This was present in 6 cases out of $20(30 \%)$.

Pattern II demonstrated that the width of the canal increased gradually from L1 down to L5. This type was observed in 5 cases out of 20 (25\%).

Pattern III demonstrated that the width of the canal remained constant from L1 to L2 lumbar vertebra then it narrowed at the level of L3 to widen at L4 and L5 (3 cases out of $20 ; 15 \%)$.

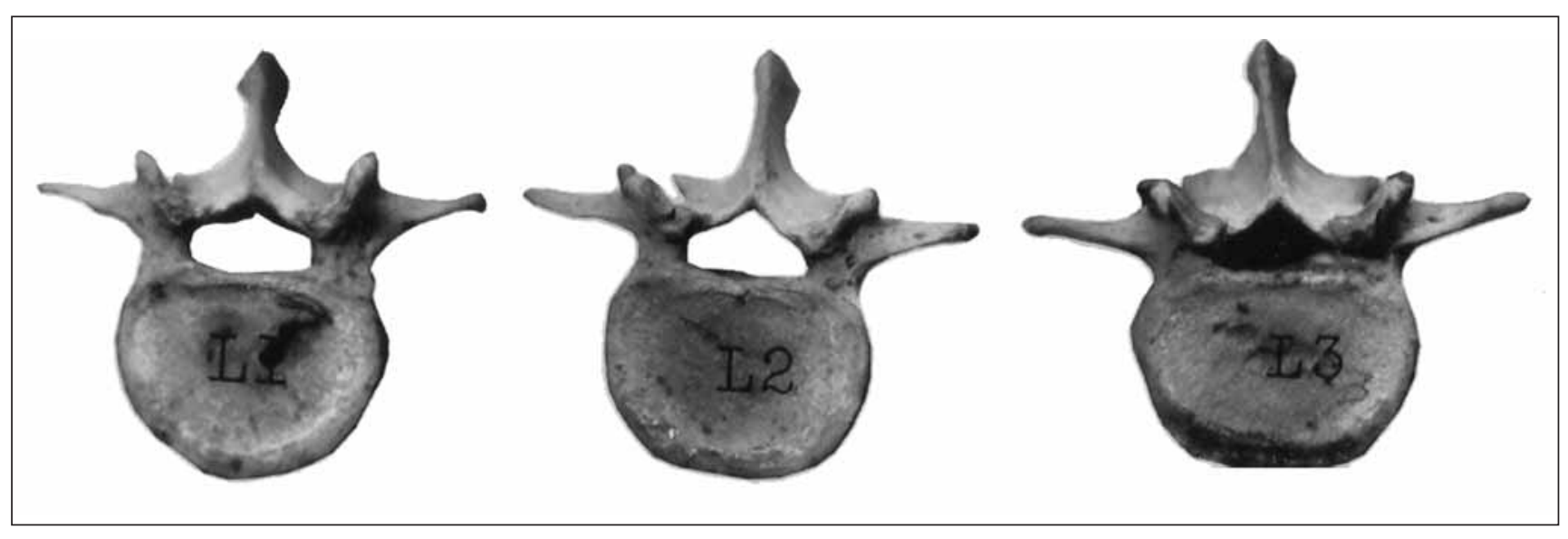

Figure 5. Photographs showing superior views of the upper three lumbar vertebrae (L1, L2 and L3) of the same individual. The lumbar vertebral foramen is oblong in shape in L1 and triangular in shape in L2 and L3 with the base directed anteriorly and the apex directed posteriorly. The vertebral foramen of the 3rd lumbar vertebra (L3) shows acute lateral angles than those of the L1 and L2. 
Pattern IV demonstrated that the canal narrowed from L1 to L2 then remained constant from L2 to L3 and finally widened down till L5 (3 cases out of 20; $15 \%)$.

Pattern $\mathbf{V}$ demonstrated that the width of the canal remained constant till the level of L4 then widened till L5 (2 cases out of $20 ; 10 \%)$.

Pattern VI demonstrated that the canal narrowed gradually from L1 reaching the narrowest diameter at L3 then widened down till L5 (one case out of 20; 5\%).

On examination of $200 \mathrm{X}$-rays, anteroposterior and lateral views revealed the following data concerning the lumbar vertebrae:

With comparison of the average widths (means) of the lumbar vertebral bodies in both sexes, the study showed that in males, the means increased slightly and steadily from $39.4 \mathrm{~mm}$ at L1 to $45.5 \mathrm{~mm}$ at L4, then it showed a relatively marked increase to $51.6 \mathrm{~mm}$ at $\mathrm{L} 5$. In females, the mean width increased also gradually from $37.5 \mathrm{~mm}$ at L1 to $49.4 \mathrm{~mm}$ at L5. Generally, the width of the lumbar vertebral bodies was greater in male than female at all lumbar levels and it was significant at L2, L3, L4 and L5; however, it was insignificant at L1 (Table 3).

In males, the mean of the transverse diameter of the vertebral foramen (interpedicular distance) was increasing from above downward throughout the lumbar region, being $23.2 \mathrm{~mm}$ at $\mathrm{L} 1,24.0 \mathrm{~mm}$ at $\mathrm{L} 2$, then 24.5 $\mathrm{mm}$ at L3, $25.4 \mathrm{~mm}$ at $\mathrm{L} 4 \mathrm{~mm}$ and finally increased to $25.9 \mathrm{~mm}$ at L5. In females, the mean width of interpeduncular distance was increasing from 23.5 at L1, then 24.0 at L2, then 24.3 at L3, 24.7 at L4 and finally it showed marked increase to 25.7 at L5. Comparison of average widths (means) of lumbar vertebral foramina showed no significant difference between males and females (Table 4).

Table 1

Means (in mm) of the width (VFD) and depth (VFD) of lumbar vertebral foramina and vertebral body width (VBW) in dry bones

\begin{tabular}{cccc}
\hline Level & $\begin{array}{c}\text { VFW (Vertebral } \\
\text { foramen width) }\end{array}$ & $\begin{array}{c}\text { VFD (Vertebral } \\
\text { foramen depth) }\end{array}$ & $\begin{array}{c}\text { VBW (Vertebral } \\
\text { body width) }\end{array}$ \\
\hline L1 & 21.6 & 14.9 & 35.8 \\
\hline L2 & 22.5 & 15.0 & 38.8 \\
\hline L3 & 21.4 & 13.4 & 40.3 \\
\hline L4 & 23.5 & 15.4 & 39.0 \\
\hline L5 & 25.1 & 15.6 & 47.1 \\
\hline
\end{tabular}

Table 2

Ratio of vertebral foramen width (VFW) to vertebral body width (VBW) of lumbar vertebrae at different levels in both dry bone (A) and radiological study (B)

\begin{tabular}{ccc}
\hline Level & VFW/VBW (A) & VFW/VBW (B) \\
\hline L1 & 0.60 & 0.57 \\
\hline L2 & 0.60 & 0.56 \\
\hline L3 & 0.53 & 0.56 \\
\hline L4 & 0.60 & 0.53 \\
\hline L5 & 0.53 & 0.51 \\
\hline
\end{tabular}


Figure 6. Photographs of superior views of fourth (a) and fifth (b) lumbar vertebrae showing nearly trefoil-shaped vertebral foramen with acute lateral angles (arrows).
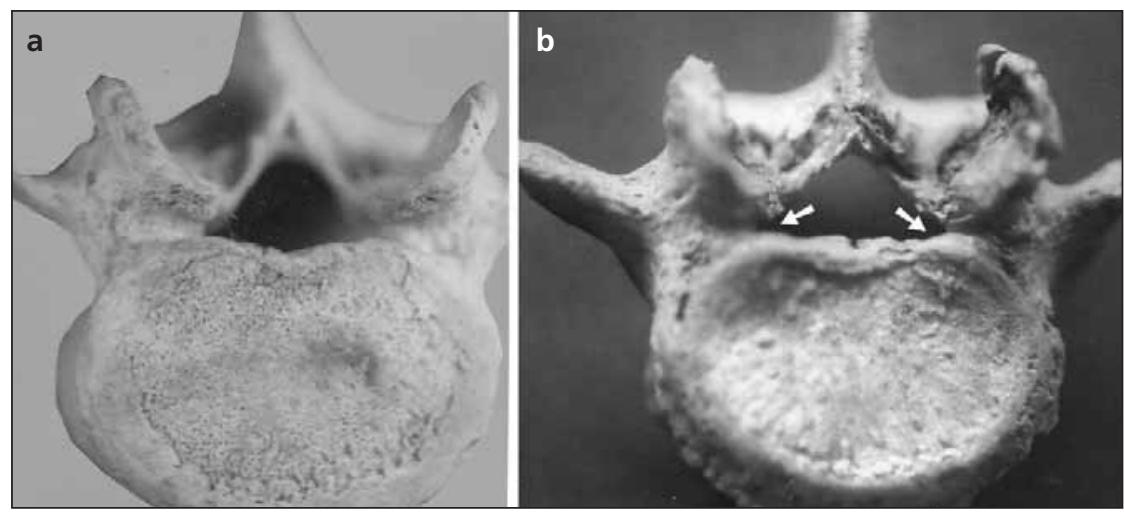

According to the width (transverse diameter, interpedicular distance) of the lumbar vertebral foramina (VFW), the radiological study showed the following morphological classification of the vertebral canal according to whether the canal widened, remained constant or was narrowed.
Figure 7. Diagrams showing the different morphological patterns of the lumbar vertebral canal.

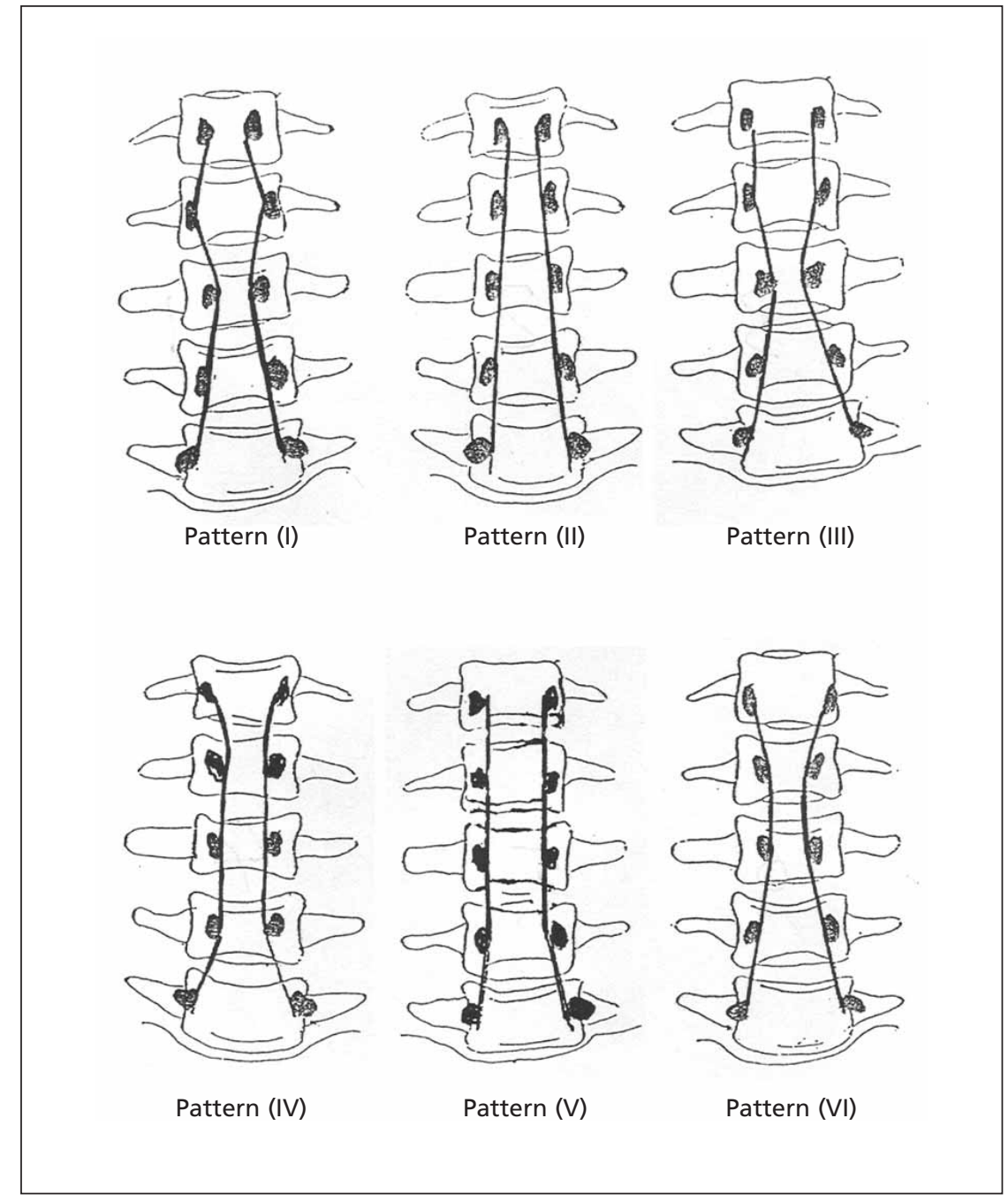


Table 3

Comparison of average widths (means in $\mathrm{mm}$ ) of lumbar vertebral bodies between males and females in radiological study

\begin{tabular}{cccccc}
\hline \multirow{2}{*}{ Level } & \multicolumn{3}{c}{ Males } & \multicolumn{2}{c}{ Females } \\
\cline { 2 - 5 } & Mean & Range & Mean & Range & t-test value \\
\hline L1 & 39.5 & $31.8-47.3$ & 37.5 & $29.8-45.3$ & 1.71 \\
\hline L2 & 40.4 & $33.5-47.3$ & 38.0 & $31.6-44.4$ & $2.15^{*}$ \\
\hline L3 & 43 & $37.0-49.0$ & 40.0 & $31.2-48.8$ & $2.88^{*}$ \\
\hline L4 & 45.5 & $40.4-50.6$ & 43.3 & $35.9-50.7$ & $2.51^{*}$ \\
\hline L5 & 31.6 & $44.7-58.6$ & 49.4 & $40.9-57.9$ & $2.03^{*}$ \\
\hline
\end{tabular}

*: significant difference

\section{Widening lumbar vertebral canal}

This pattern occurred where the canal generally widened from above downward. This type constituted the majority of cases (82 out of 200; $41 \%$ ) and was divided into two types whether the canal widened with or without narrowing:

Type (A): When the width of canal increased with narrowing at one or two segments. This type was present in 50 out of 82 cases $(61 \%)$. It could be divided into the following subtypes according to the level of narrowing:

Subtype 1: Narrowing was at L4. This was present in 25 out of 48 cases $(52.1 \%)$.

Subtype 2: Narrowing was at L3. This was present in 19 out of 48 cases (39.7\%).
Subtype 3: Narrowing was at L5. This was present in 2 out of 48 cases $(4.1 \%)$.

Subtype 4: Narrowing was at two levels. It was present in 2 out of 48 cases ( $4.1 \%)$.

Type (B): When the width of canal increased without any narrowing. This type was present in 32 out of 82 cases $(39 \%)$.

\section{Constant lumbar vertebral canal}

This pattern occurred when the width of the canal remained constant till a level and then either increased or became irregular. It was present in 78 out of 200 cases (39\%). According to the level where the canal starts to increase or become irregular, it was divided into:

Table 4

Comparison of average widths (means in $\mathrm{mm}$ ) of lumbar vertebral foramina between males and females in radiological study

\begin{tabular}{cccccc}
\hline \multirow{2}{*}{ Level } & \multicolumn{2}{c}{ Males } & \multicolumn{2}{c}{ Females } & \\
\cline { 2 - 5 } & Mean & Range & Mean & Range & t-test value \\
\hline L1 & 23.2 & $17.2-29.2$ & 23.5 & $17.3-29.8$ & 0.35 \\
\hline L2 & 24 & $18.9-29.2$ & 24.0 & $18.8-29.3$ & 0 \\
\hline L4 & 24.5 & $19.8-29.2$ & 24.3 & $19.7-29.0$ & 0.31 \\
\hline L5 & 25.4 & $19.8-31.0$ & 24.7 & $19.5-31.0$ & 0.88 \\
\hline
\end{tabular}


Pattern 1: The canal was constant from L1 to L2 then either became irregular or increased. This pattern was present in 66 out of 78 cases (84.6\%) and was subclassified into:

a. Irregular canal: Presented in 34 out of 66 cases $(51.5 \%)$.

b. Increasing canal: Presented in 32 out of 66 cases (48.5\%).

Pattern 2: The canal was constant from L1 to L4 then increased down to L5. This pattern was present in 10 out of 78 cases $(12.8 \%)$.

Pattern 3: The canal was constant from L1 to L3 then increased down to L5. This pattern was present in 2 out of 78 cases $(2.6 \%)$.

\section{Narrowing lumbar vertebral canal}

This pattern occurred when the canal generally decreased in width from above downward. This was present in 40 out of 200 cases (20\%). It was divided into two classes according to whether the canal decreased generally down to L5 or became widened at certain segments.

Class 1: When the canal was generally narrowed (36 out of 40 cases; $90 \%$ ) but widened either at L4 to L5 (28 out of 36 cases; $77.8 \%$ ) or at L3 to L5 (8 out of 36 cases; $22.2 \%)$.

Class 2: When the canal generally narrowed without any widening. This was present in 4 out of 40 cases (10\%).
In males, the mean anteroposterior diameters of the vertebral foramina (VFD) increased from $13.1 \mathrm{~mm}$ at L1 to $14.6 \mathrm{~mm}$ at L2, then decreased gradually to $9.9 \mathrm{~mm}$ at L5. In females, the mean anteroposterior diameters of the foramina increased also from $13.2 \mathrm{~mm}$ at $\mathrm{L} 1$ to 13.4 $\mathrm{mm}$ at L2 then decreased gradually reaching $9.5 \mathrm{~mm}$ at L5. Comparison of the average means of the anteroposterior diameters between males and females showed significant differences at the levels of L2, L3 and L4 however, at the level of L1 and L5 the means were insignificant statistically (Table 5).

\section{Discussion}

The assessment of the size of the vertebral canal is an important diagnostic procedure for low-back pain of unknown etiology. The configuration of the lumbar vertebral canal is determined by the structures bounding the successive vertebral foramina and any pathological changes in the diameter of the canal might be associated with low-back pain.

In the present study, the shape of the lumbar vertebral foramen was nearly oblong with wide transverse diameter in the upper lumbar region (L1 and L2) while in the lower region (L4 and L5) the shape of the vertebral foramen was nearly trefoil or was assumed a "Napoleon's hat-like" shape as described by Speciale et al. ${ }^{8}$ and Panjabi et al. ${ }^{18}$ In the mid-lumbar region (L3) the foramen was triangular. These findings are in agreement

Table 5

Comparison of average antero-posterior diameters (means in $\mathrm{mm}$ ) of lumbar vertebral foramina between males and females in radiological study

\begin{tabular}{|c|c|c|c|c|c|}
\hline \multirow[t]{2}{*}{ Level } & \multicolumn{2}{|c|}{ Males } & \multicolumn{2}{|c|}{ Females } & \multirow[b]{2}{*}{ t-test value } \\
\hline & Mean & Range & Mean & Range & \\
\hline L1 & 13.1 & $10.0-16.2$ & 13.2 & $10.0-16.3$ & 0.23 \\
\hline L2 & 14.6 & $11.6-17.7$ & 13.4 & $10.7-16.2$ & $2.39 *$ \\
\hline L3 & 12.3 & 9.8-14.9 & 11.5 & $9.0-14.1$ & $2.29 *$ \\
\hline L4 & 11.7 & $9.4-14$ & 11 & $8.9-13.2$ & $2.26^{\star}$ \\
\hline L5 & 9.9 & $8.2-11.6$ & 9.5 & $7.5-10.9$ & 1.67 \\
\hline
\end{tabular}

*: significant difference 
with Weinstein ${ }^{23}$ who mentioned that the lumbar vertebral canal was roughly triangular in shape especially at L3 and was narrowest in its anteroposterior diameter in the lower lumbar segments.

The present study recorded that the mean width of the lumbar vertebral foramen increased gradually in both dry bones and X-rays from L1 to L5 except with a slight drop at L3 in the dry bones. This finding is in contrary to that of Amonoo-Kuofi ${ }^{7}$ and Speciale et al. ${ }^{8}$ who found that the width was constant in L1 and L2, then increased gradually till L5. This finding of the present study is also in contrary to the finding of Zindrick et al. ${ }^{1}$ who have reported a decreasing diameter of lumbar vertebral foramen from L1 to L5. The present work revealed that the widest diameter was at L5 level while the narrowest was at L3 level in dry bones and at L1 in radiological images. The mean width of the vertebral foramen (as determined in dry bone and radiological study) was ranged between 21.6 to $25.1 \mathrm{~mm}$. Haig et al., ${ }^{11}$ Weinstein, ${ }^{23}$ Verbiest, ${ }^{24}$ and Jane et al. $^{25}$ noted that lumbar canal width, ranging from 10 to $12 \mathrm{~mm}$ might be associated with claudication if additional soft or hard tissue elements encroached on the canal, and they referred to this type of stenosis as "relative" canal stenosis. The diameters observed in the present study were in contrary to those of Williams et al. ${ }^{26}$ who reported a gradual decrease in measurement between L1 and L5 level, with a greater relative width in females, however, the present study did not show any significant differences in the average widths (means) of lumbar vertebral foramina between males and females.

In the present study, the mean depth of the vertebral foramen (anteroposterior diameter) showed different values through out lumbar canal. In the dry bone study, the mean depth showed an increase from $14.9 \mathrm{~mm}$ at L1 to $15.6 \mathrm{~mm}$ at $\mathrm{L} 5$, with a slight drop at $\mathrm{L} 3$ level. This is in agreement with Amonoo-Kuofi ${ }^{9}$ who has reported a similar finding. In the radiological study the mean depth in males showed an initial increase from $13.1 \mathrm{~mm}$ at L1 to $14.6 \mathrm{~mm}$ at $\mathrm{L} 2$, then decreased gradually reaching 9.9 $\mathrm{mm}$ at L5. In females the depth of the vertebral foramen showed an initial increased from $13.2 \mathrm{~mm}$ at L1 to 13.4 $\mathrm{mm}$ at L2 then dropped to $11.5 \mathrm{~mm}$ at L3 and finally reached to $9.5 \mathrm{~mm}$ at $\mathrm{L} 5$. The deepest vertebral foramen was $14.6 \mathrm{~mm}$ at the level of L2 in radiological study, while it was $15.6 \mathrm{~mm}$ at the level L5 in dry bone study. Narrowest anteroposterior diameter of the vertebral foramen was $9.9 \mathrm{~mm}$ at the level of $\mathrm{L} 5$ in radiological study while it was $13.4 \mathrm{~mm}$ at the level of L3 in dry bone study. While comparing, the average means of the anteroposterior diameters between males and females, the present study showed significant differences at the levels L2, L3 and L4 however, at the levels of L1 and L5 the means were insignificant. As reported in the literature, the average anteroposterior diameter of the lumbar canal in adults ranged from 15 to $23 \mathrm{~mm}$ or between 15 $19 \mathrm{~mm}$ as recorded by Rothman et al. ${ }^{23,27}$ However, in the current study it ranges between 9.9 and $15.6 \mathrm{~mm}$ and is less than the earlier findings.

Geisser et al., ${ }^{12}$ and Shatzkir and Pennal ${ }^{28}$ noticed that under the normal conditions, there is a small free space between the lumbar vertebral canal and its contents allowing free movement of the contents without tension or pressure during movements of lumbar vertebral column. Abnormal reduction of this small free space between the lumbar vertebral canal and its contents would cause vertebral canal stenosis. The narrow osseous anteroposterior diameter of the vertebral foramen as found in the present work, causes the canal stenosis. The cone-shaped terminus of the spinal cord (conus medullaris) normally ends at about the L1 or L2 level in adults. Caudal to these levels, the roots of the cauda equina are contained within the subarachnoid space of the dura-enclosed thecal sac. Thus, canal stenosis at lumbar levels results in nerve root dysfunction rather than spinal cord dysfunction.

Published papers, on the vertebral foramen depth, by Hinck et al. ${ }^{29}$ on American subjects, Eisenstein ${ }^{30}$ on South African subjects, Amonoo-Kuofi ${ }^{7}$ on Nigerians, Postacchini et al. ${ }^{31}$ on Italians and Indians, Piera et al. ${ }^{32}$ on Spaniards, Amonoo-Kuofi et al. ${ }^{13}$ on Saudi subjects reported different configurations that should be cautiously dealt with specially in management of cases with low-back pain due to vertebral canal stenosis. These differences might be attributed to racial, ethnic and/or environmental factors. 
Comparative analysis of the interpedicular distance (vertebral foramen width) by Amonoo-Kuofi, ${ }^{7}$ AmonooKuofi et al., ${ }^{13}$ Postacchini et al., ${ }^{31}$ and Piera et al. ${ }^{32}$ suggested that there are morphometric differences between different populations. The interpedicular diameters of the Egyptians lumbar vertebrae, in the current study, are different from those of Saudis and Americans. ${ }^{13,29}$ Egyptian lumbar interpedicular diameter are larger than those of Nigerians, Negroid and Caucasoid South Africans and smaller than Spanish vertebrae. ${ }^{7,30,32}$ The lowest interpedicular diameter of the Egyptians recorded in this study was $21.6 \mathrm{~mm}$ which is larger than that of recorded for Canadians $\left(17 \mathrm{~mm}\right.$ ) by Weir and $\mathrm{Leo}^{33}$ and is nearly equal to that of Germans $(22 \mathrm{~mm})$ as reported by Lazorthes ${ }^{34}$ and for Italians and Indians $(22 \mathrm{~mm})$ by Postachini et al. ${ }^{31}$

Correlation between the width of the lumbar vertebral canal and that of the vertebral bodies showed a positive relation, where the interpedicular diameter proportionally increased with the transverse diameter of the body. This is in accordance with the concept of Weisz and Lee. ${ }^{35}$ This relation is so steady that the ratio between the two was found to be constant (0.6) only at L1, L2 and L4. This ratio is equal to that estimated in Nigerians ${ }^{7}$ and Saudis, ${ }^{13}$ which was also 0.6 in both cases. In this study, at L3 and L5 the ratios are different and both are equal, being 0.5 and this signifies that at these two levels the vertebral bodies are larger than the canal and are thus susceptible to stenosis. In radiological study, the ratio between the width of lumbar vertebral canal and lumbar vertebral body is also 0.6 at L1, L2 and L3 but it becomes 0.5 at L4 and L5.

\section{Conclusion}

The present study has shown a narrower depth of the lumbar vertebral canal in Egyptian population. Width of the lumbar vertebral canal is more in lower segment with a narrowing at L3 while the depth of the lumbar vertebral foramina is narrower in lower segment. L3 remains the center point for transition in the dimensions and hence more susceptible to stenosis and spinal nerve compression.
This study has also shown that the ratio between the width of body and foramen of lumbar vertebrae remains constant. Any changes in this ratio may predict any lumbar vertebral anomalies or vertebral canal stenoses.

\section{References}

1. Zindrick MR, Wiltse LL, Widell HE. A biomechanical study of intrapeduncular screw fixation in the lumbosacral spine. Clin Orbtop 1986; 203: 99-112.

2. Amundsen T, Weber H, Lilleas F, Nordal HJ, Adelnoor M, Magnaes B. Lumbar spinal stenosis: clinical and radiologic features. Spine 1995; 20: 1178-86.

3. Santiago FR, Milena GL, Herrera RO, Romero PA, Plazas PG. Morphometry of the lower lumbar vertebrae in patients with and without low back pain. Eur Spine 7 2001; 10: 228-33.

4. Christenson PB. The radiologic study of the normal spine. Radiol Clin North Am 1977; 31: 147-57.

5. Schonstrom NS, Bolender N, Spengler DM. The pathomorphology of spinal stenosis as seen on CT scans of the lumbar spine. Spine 1985; 10: 806-11.

6. Hamanashi C, Matukura N, Fujita M, Tomihara M, Tanaka S. Cross-sectional area of the stenotic dural tube measured from the transverse views of magnetic resonance imaging. 7 Spinal Dis 1994; 7: 388-93.

7. Amonoo-Kuofi HS. Maximum and minimum lumbar interpedicular distances in normal adult Nigerians. F Anat 1982; 135: 225-33.

8. Speciale AC, Pietrobon R, Urban CW, et al. Observer variability in assessing lumbar spinal stenosis severity on magnetic resonance imaging and its relation to cross-sectional spinal canal area. Spine 2002; 27: 1082-6.

9. Amonoo-Kuofi HS. The sagittal diameter of the lumbar vertebral canal in normal adult Nigerians. F Anat 1985; 140: 69-78.

10. Swanson KE, Lindsey DP, Hsu KY, Zucherman JF, Yerby SA. The effects of an interspinous implant on the intervertebral disc pressure. Spine 2003; 28: 26-32.

11. Haig AJ, Geisser ME, Tong HC, et al. Electromyographic and magnetic resonance imaging to predict lumbar stenosis, low-back pain, and no back symptoms. 7 Bone foint Surg Am 2007; 89: 35866.

12. Geisser ME, Haig AJ, Tong CH, et al. Spinal canal size and clinical symptoms among persons diagnosed with lumbar spinal stenosis. Clin 7 Pain 2007; 23: 780-5.

13. Amonoo-Kuofi HS, Patel PJ, Fatani JA. Transverse diameter of the lumbar spinal canal in normal adult Saudies. Acta Anat 1990; 137: $124-8$.

14. Agur AM. Grant's Atlas of Anatomy. 9th ed. Baltimore: Williams and Wilkins; 1991. p. 250. 
15. Garfin SR, Rydevik BL, Lipson SJ. Spinal stenosis. In: Rothman Rh, Simeone FA, eds. The Spine. 3rd ed. Philadelphia: WB. Saunders; 1992. p. 791-856.

16. Ciricillo SF, Weinstein PR. Lumbar spinal stenosis. West 7 Med 1993; 158: 171-7.

17. Zarzur E. The shape of the human lumbar vertebral canal. Arq Neuropsiquiatr 1996; 54: 451-4.

18. Panjabi MM, Goel V, Oxland T, et al. Human lumbar vertebrae: quantitative three-dimensional anatomy. Spine 1992; 17: 299-306.

19. Keegan JJ. Alteration of the lumbar curve related to posture and seating. 7 Bone foint Surg Am 1953; 35: 589-603.

20. Milton JS, Tsokos JO. Statistical Methods in the Biological and Health Sciences. International student ed. Tokyo: Kosaido Printing Co. Ltd.; 1983. p. 233-8.

21. Grados F, Fardellone P, Benammar M, Muller C, Roux C, Sebert JL. Influence of age and sex on vertebral shape indices assessed by radiographic morphometry. Osteoporos Int 1999; 10: 450-5.

22. Weber F, deKlerk DJ. Spinal stenosis. South Afr Med 7 1973; 47: 207-13.

23. Weinstein PR. Anatomy of the lumbar spine. In: Hardy, RW Jr, ed. Lumbar Disc Disease. 2nd ed. New York: Raven Press; 1993. p. $5-13$.

24. Verbiest H. Lumbar spinal stenosis. In: Youngman's Neurological Surgery: Comprehensive References Guide to the Diagnosis and Management of Neurosurgical Problems. 3rd ed. Philadelphia: Saunders; 1990. p. 2805-55.

25. Jane JA, Helm GA, Kallmes DF, Shaffrey JB. Acquired lumbar stenosis. In: Clinical Neurosurgery. Baltimore: Williams \& Wilkins; 1995. p. 275-99.
26. Williams P, Bannister L, Berry, et al. Gray's Anatomy. 38th ed. Edinburgh: Churchill Livingstone; 1995. p. 512, 513, 515, 526, $527,536$.

27. Rothman RH. The clinical syndrome of lumbar disc disease. Orthop Clin North Am 1971; 2: 463-75.

28. Shatzker J, Pennal GE. Spinal stenosis, a cause of cauda equina compression. 7 Bone foint Surg Br 1968; 50: 606-18.

29. Hinck VC, Clark WM Jr, Hopkins CE. Normal interpedicular distances (minimum and maximum) in children and adults. Am 7 Roentgenol 1966; 97: 141-53.

30. Eisenstein MG. The morphometry and pathological anatomy of the lumbar spine in South Africa Negroes and Caucasoids with specific reference to spinal stenosis. 7 Bone foint Surg Br 1977; 59: 173-180.

31. Postacchini F, Ripani M, Carpano S. Morphometry of the lumbar vertebrae: an anatomic study in two Caucasoid ethnic groups. Clin Orthop Relat Res 1983; (172): 296-303.

32. Piera V, Rodriguez A, Cobos A, Hernandez R, Cobos P. Morphology of lumbar vertebral canal. Acta Anat 1988; 131: 3540.

33. Weir B, Leo R. Lumbar stenosis: analysis of factors affecting outcome in 81 surgical cases. Can 7 Neurol Sci 1981; 8: 295-8.

34. Lazorthes C. Le systeme nerveux central. 3rd ed. Paris: Masson; 1983. p. 31-3.

35. Weisz GM, Lee P. Spinal canal stenosis. Concept of spinal reserve capacity: radiologic measurements and clinical applications. Clinic Orthop Relat Res 1983; 179: 134-40.

Correspondence to: Abd El-Rahman El-Shahat, MD Department of Anatomy, Faculty of Medicine, Cairo University, Cairo, Egypt e-mail: Shaikhm.63@gmail.com

Conflict of interest statement: No conflicts declared. 